\title{
Obesity: new insight into the anthropometric classification of fat distribution shown by computed tomography
}

\author{
MARGARET ASHWELL, T J COLE, A K DIXON
}

\begin{abstract}
Twenty eight women presenting for routine computed tomography had their waist, hip, and thigh circumferences measured. The ratio of the area of intra-abdominal fat to the area of subcutaneous fat shown in the computed tomogram taken at the umbilical level was calculated and found to correlate highly significantly with the ratio of waist to hip circumference. The correlation between these two ratios remained significant after allowing for the degree of obesity (weight $\left.(\mathrm{kg}) / \mathrm{height}(\mathrm{m})^{2}\right)$ and age. In contrast, there was no significant correlation between the ratio of intra-abdominal to subcutaneous fat and degree of obesity.

A high ratio of waist to hip circumference has been shown to be associated with a high proportion of intra-abdominal fat. Thus women with a centralised distribution of fat (high waist to hip ratio: "apples") tend to have a greater proportion of their fat in the intra-abdominal depot than do women with a peripheral fat distribution (low waist to hip ratio: "pears").

The metabolic complications of obesity, which are associated with a high ratio of waist to hip circumference, may therefore relate specifically to the amount of intra-abdominal fat.
\end{abstract}

\section{Introduction}

The metabolic implications of the distribution of body fat have recently received considerable attention.' Vague was the first to point out that "android" or centralised obesity was more closely associated with diabetes, gout, and atherosclerosis than the more peripheral "gynaecoid" obesity. ${ }^{2}$ Researchers in Wisconsin classified fat distribution in women on the basis of the ratio of waist to hip circumference..$^{3.5}$ They found that this ratio was a significant predictor of plasma triglyceride, glucose, and insulin concentrations and correlated with an in vivo index of insulin resistance. ${ }^{5}$ In Gothenburg Krotkiewski et al also found that it was the women with high waist to hip circumference ratios who were most likely to suffer these metabolic abnormalities of obesity, ${ }^{6}$ and prospective studies of risk factors for ischaemic heart disease in men $^{7}$ and women ${ }^{8}$ found that the waist to hip circumference ratio was a better predictor for ischaemic heart disease than the degree of adiposity.

Both the Wisconsin and the Gothenburg groups have suggested why this ratio correlates with the observed metabolic aberrations of obesity. Kissebah et al took needle biopsy specimens of subcutaneous fat cells from the abdomen and thigh and showed that the abdominal fat cells of women with a centralised distribution of fat were larger and exhibited a higher rate of lipolysis than those from women with a peripheral distribution of fat. They suggested that the presence of these hypertrophied subcutaneous fat cells with their high output of free fatty acids could be an important factor in the susceptibility of

Medical Research Council Dunn Nutrition Unit, Cambridge CB4 1X

MARGARET ASHWELL, PHD, member of scientific staff

T J COLE, PHD, member of scientific staff

Department of Radiology, University of Cambridge, Addenbrooke's Hospital, Cambridge CB2 $2 Q Q$

A K DIXON, MRCP, FRCR, lecturer, honorary consultant radiologist

Correspondence to: Dr M Ashwell. these women with centralised obesity to glucose intolerance, hyperinsulinaemia, and hypertryglyceridaemia. On the other hand, the Gothenburg group suggested that the relation between waist to hip circumference ratio and the observed metabolic aberrations might depend on the increased accumulation of intra-abdominal fat cells and that the abnormalities might arise from the unique position of these fat cells to the portal circulation. Thus it is important to investigate the actual distribution of fat between the intra-abdominal and subcutaneous fat depots and, in particular, how this distribution relates to waist to hip circumference ratio and other anthropometrically derived variables.

Unfortunately, the classification of the distribution of fat from anthropometric findings can distinguish only those with a centralised distribution ("apples") from those with a peripheral distribution ("pears). Anthropometry cannot differentiate between the intraabdominal and subcutaneous fat depots, and, indeed, until recently little was known about the relative distribution of fat between these depots. ${ }^{910}$ Intra-abdominal fat may now, however, be assessed by computed tomography. ${ }^{11 \cdot 14}$ Computed tomography provides thin, cross sectional, radiographic images that may be obtained at any level in the body. Fat is easily recognised by its low attenuation. In the abdomen this feature permits the calculation of the cross sectional areas of both intra-abdominal and subcutaneous fat.

Whereas anthropometry may be used to assess the relative distribution of fat in large numbers of patients this is obviously not feasible with computed tomography. We therefore studied distribution of fat with both techniques in a small group of women who were undergoing routine computed tomography for other reasons.

\section{Patients and methods}

Patients-Over two months all women referred for computed tomography on one particular day of the week were considered for entry into the study. Patients with known diabetes, possible Cushing's syndrome, receiving large doses of steroids, or with abnormal findings from computed tomography were excluded. Many of the remaining patients proved to be thin. Thus to ensure a range of differing degrees of obesity the fatter patients were preferentially selected. By the end of the period 28 such patients had been evaluated ranging in age from 23 to 73 years and in weight from 50 to $137 \mathrm{~kg}$ (table I).

TABLE I-Details of 28 women attending for computed tomography

\begin{tabular}{lcc}
\hline & Mean $(\mathrm{SD})$ & Range \\
\hline Age $($ years $)$ & $47(15)$ & $23-37$ \\
Weight $(\mathrm{kg})$ & $70(18)$ & $50-137$ \\
Height $(\mathrm{m})$ & $1 \cdot 61(0 \cdot 07)$ & $1 \cdot 44-1 \cdot 71$ \\
Obesity index (weightheight $\left.{ }^{2}\right)$ & $26 \cdot 7(6 \cdot 1)$ & $20 \cdot 3-48 \cdot 5$ \\
Waist circumference $(\mathrm{cm})$ & $82(14 \cdot 0)$ & $63-129$ \\
Hips circumference $(\mathrm{cm})$ & $103(12 \cdot 5)$ & $85-144$ \\
Thigh circumference $(\mathrm{cm})$ & $59(9 \cdot 0)$ & $46-80$ \\
Waist:hip ratio & $0 \cdot 79(0 \cdot 06)$ & $0 \cdot 69-0 \cdot 92$ \\
Waist:thigh ratio & $1 \cdot 40(0 \cdot 16)$ & $0 \cdot 99-1 \cdot 65$ \\
Total fat area $\left(\mathrm{cm}^{2}\right)$ & $364(167)$ & $105-892$ \\
Total intra-abdominal fat area $\left(\mathrm{cm}^{2}\right)$ & $85(58)$ & 13.246 \\
Total subcutaneous fat area $\left(\mathrm{cm}^{2}\right)$ & $279(122)$ & $92-646$ \\
Intra-abdominal fat:subcutaneous fat ratio & $0 \cdot 31(0 \cdot 16)$ & $0 \cdot 09-0.61$ \\
\end{tabular}

Computed tomography-In each patient the computed tomogram taken immediately cranial to the iliac crests was chosen for further analysis. Such a level usually traverses the body of the fourth lumbar vertebra and is close to the umbilicus in most patients. By means of describing regions of interest with a light pen cursor and assessing the number of pixels within the fat density range ( -150 to -50 Hounsfield Units) the cross sectional areas of both intra-abdominal and subcutaneous fat were calculated as previously 
described. ${ }^{11}$ As the region of interest for intra-abdominal fat passes through rectus abdominis, internal oblique, and quadratus lumborum the intraabdominal fat measurement includes retroperitoneal, mesenteric, and omental fat (figure).

Anthropometry-After computed tomography a thin tape was used to measure minimum waist girth, maximum hip girth, and thigh circumference as described by Ashwell et al. ${ }^{15}$ From these measurements the ratios of waist to hip circumference and of waist to thigh circumference were calculated. Body weight $(\mathrm{kg})$ and standing height $(\mathrm{m})$ were also measured, allowing the obesity index (weight/height ${ }^{2}$ ) to be calculated. This index shows a high correlation with total body fat. ${ }^{16}$ waist to hip $(p<0.001)$ and waist to thigh $(p<0.01)$ ratios but showed no significant correlation with the obesity index. This was not too surprising as the obesity index correlated significantly $(p<0.001)$ with both intraabdominal and subcutaneous fat whereas the anthropometric ratios did not.

Table III shows the significance, expressed as $t$ values, of the correlations between the anthropometric variables and the body fat variables both before and after adjusting for age and obesity index. It is clear that, after adjustment, only the ratio of waist to hip circumference retained a significant positive correlation with the ratio of intra-abdominal to subcutaneous fat $(\mathrm{p}<0.01)$.
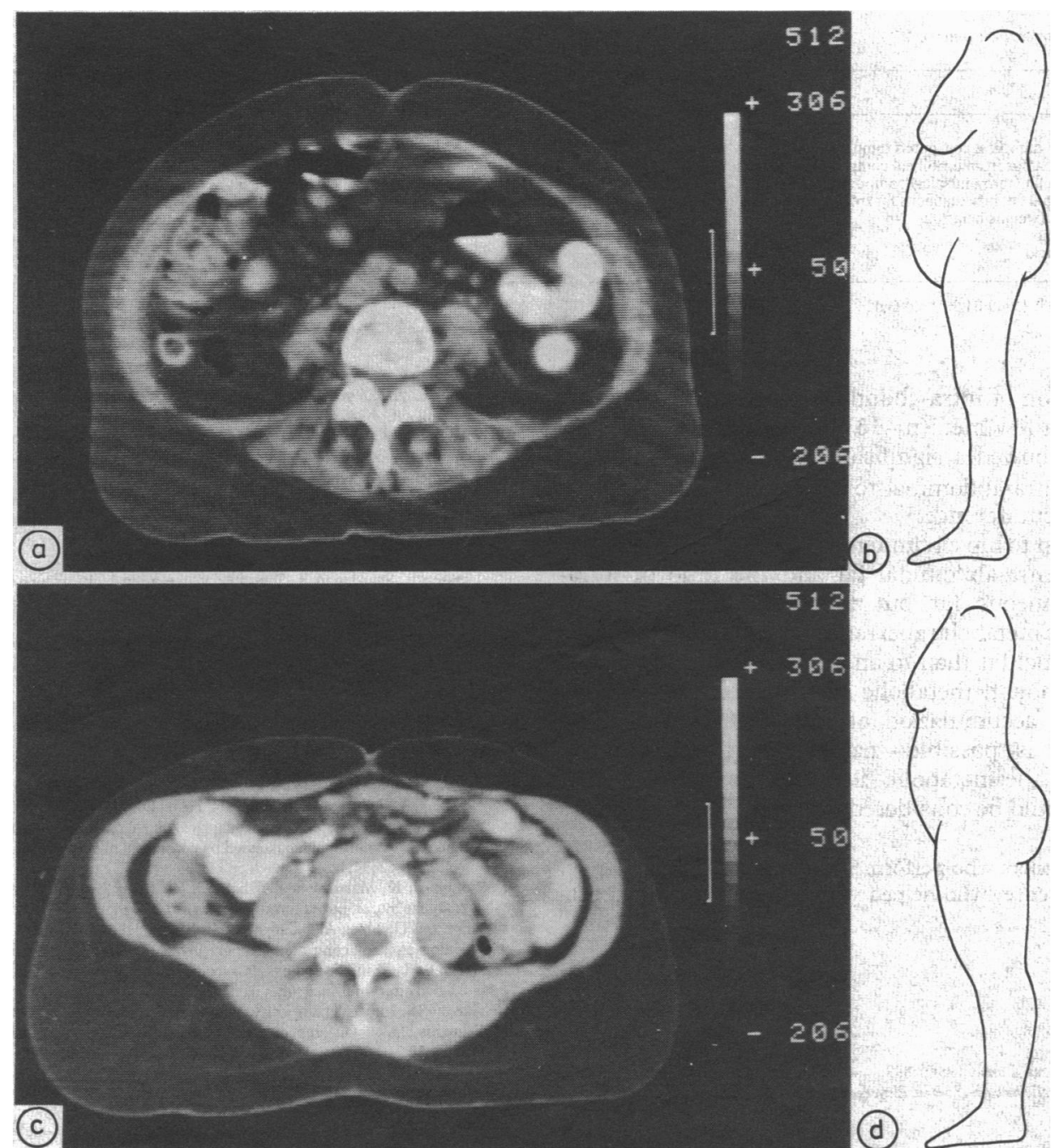

(a) Computed tomogram of a 67 year old woman being investigated because of gynaecological malignancy. Height $149 \mathrm{~cm}$; weight $56 \mathrm{~kg}$; waist:hip ratio 0.87 ; waist:thigh ratio $1 \cdot 57$; weight/height $25 \cdot 22$; intra-abdominal fat $120 \mathrm{~cm}^{2}$; subcutaneous fat $208 \mathrm{~cm}^{2}$; intra-abdominal:subcutaneous fat ratio 0.58 . (b) Tracing of photograph of representative "apple" shaped woman. (c) Computed tomogram of a 29 year old woman being investigated for possible phaeochromocytoma. Height 171 $\mathrm{cm}$; weight $67 \mathrm{~kg}$; waist:hip ratio 0.74 ; waist:thigh ratio 1.31 ; weight/height ${ }^{2} 22.91$; intra-abdominal fat $22 \mathrm{~cm}^{2}$; subcutaneous fat $218 \mathrm{~cm}^{2}$; intra-abdominal:subcutaneous fat ratio $0 \cdot 10$. (d) Tracing of photograph of representative "pear" shaped woman.

Statistical methods-Association between variables was measured by the correlation coefficient, and adjustments for age and degree of obesity were done by multiple regression. All values except for age were analysed after transformation to natural logarithms.

\section{Results}

Table I gives details of the subjects, showing a wide age range and a large variation in degree of obesity. The women also varied widely in distribution of fat as reflected by the anthropometric findings and derived ratios.

Table II shows a correlation matrix of the variables listed in table I. The ratio of intra-abdominal to subcutaneous fat correlated significantly with the

\section{Discussion}

This study was prompted by the current interest in the distribution of body fat and the role that variations in distribution may have in the aetiology of the different metabolic disturbances in obese people. Until now classification of distribution of body fat has been derived mainly from anthropometry. A clear picture is emerging of possible problems in patients with centralised obesity. ${ }^{2-8}$ Until now the relation between centralised obesity and intra-abdominal fat content has not been known: do people with centralised obesity ("apples") and those with peripheral obesity ("pears") have similar proportions of intra-abdominal fat, differing only in the placement of their subcutaneous fat? 
Our findings suggest the opposite-that "apples" tend to have more intra-abdominal fat than "pears"-and that the simple calculation of waist to hip circumference ratio is a good predictor of the proportion of intra-abdominal fat. Conversely, they also suggest that the obesity index is of no value in predicting relative fat distribution.

Men are more likely than women to have a centralised type of fat distribution, ${ }^{2917}$ and computed tomography has allowed intraabdominal and subcutaneous fat to be assessed in men and women. ${ }^{12}{ }^{14}$ Dixon $^{12}$ and Grauer et $a l^{14}$ have shown that men tend to
TABLE III-Significance of correlations after adjusting for age and degree of obesity showing $t$ values on $24 \mathrm{df}$ together with $t$ values on 26 df before adjustment in parentheses

\begin{tabular}{|c|c|c|c|c|}
\hline Ratio & $\begin{array}{c}\text { Total } \\
\text { fat }\end{array}$ & $\begin{array}{c}\text { Intra-abdominal } \\
\text { fat }\end{array}$ & $\begin{array}{l}\text { Subcutaneous } \\
\text { fat }\end{array}$ & $\begin{array}{c}\text { Intra-abdominal } \\
\text { subcutaneous } \\
\text { fat }\end{array}$ \\
\hline $\begin{array}{l}\text { Waist:hip } \\
\text { ratio }\end{array}$ & $\left\{\begin{array}{l}0.53 \\
\left(2 \cdot 81^{\star \star}\right)\end{array}\right.$ & $\begin{array}{c}3 \cdot 01^{\star \star} \\
\left(4 \cdot 89^{\star \star \star}\right)\end{array}$ & $\begin{array}{c}-0.87 \\
(1.75)\end{array}$ & $\begin{array}{c}2 \cdot 98^{\star \star} \\
\left(3 \cdot 94^{\star \star \star}\right)\end{array}$ \\
\hline $\begin{array}{l}\text { Waist:thigh } \\
\text { ratio }\end{array}$ & $\left\{\begin{array}{c}0 \cdot 14 \\
(1 \cdot 14)\end{array}\right.$ & $\begin{array}{l}1 \cdot 82 \\
\left(2 \cdot 71^{\star}\right)\end{array}$ & $\begin{array}{r}-0.84 \\
(0.39)\end{array}$ & $\begin{array}{l}1.95 \\
\left(3 \cdot 15^{\star \star}\right)\end{array}$ \\
\hline
\end{tabular}

p values: ${ }^{\star}<0.05 ; \star \star<0.01 ; \star \star \star<0.001$

TABLE II-Correlation matrix

\begin{tabular}{|c|c|c|c|c|c|c|c|c|}
\hline & 1 & 2 & 3 & 4 & 5 & 6 & 7 & 8 \\
\hline $\begin{array}{l}\text { 1 Age } \\
2 \text { Total fat from umbilical computed tomogram } \\
3 \text { Intra-abdominal fat from umbilical computed tomogram } \\
4 \text { Subcutaneous fat from umbilical computed tomogram } \\
5 \text { Intra-abdominal fat:subcutaneous fat from umbilical computed tomogram } \\
6 \text { Obesity index (weight/height }{ }^{2} \text { ) } \\
7 \text { Waist:hips ratio } \\
8 \text { Waist:thigh ratio }\end{array}$ & $\begin{array}{c}1 \cdot 00 \\
0.11 \\
0.38^{\star} \\
-0.01 \\
0.48^{\star \star} \\
-0.04 \\
0.28 \\
0.44^{\star}\end{array}$ & $\begin{array}{l}1 \cdot 00 \\
0.78^{\star \star \star} \\
0.96^{\star \star \star} \\
0 \cdot 24 \\
0.91^{\star \star \star} \\
0.48^{\star \star} \\
0.22\end{array}$ & $\begin{array}{l}1 \cdot 00 \\
0 \cdot 59^{\star \star \star \star} \\
0 \cdot 79^{\star \star \star \star} \\
0 \cdot 71^{\star \star \star} \\
0 \cdot 69^{\star \star \star} \\
0.47^{\star}\end{array}$ & $\begin{array}{l}1.00 \\
-0.03 \\
0.87^{\star \star \star} \\
0.32 \\
0.08\end{array}$ & 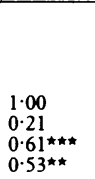 & $\begin{array}{l}1 \cdot 00 \\
0 \cdot 44^{\star \star} \\
0 \cdot 16\end{array}$ & $\begin{array}{l}1 \cdot 00 \\
0 \cdot 75^{\star \star \star}\end{array}$ & 1.00 \\
\hline
\end{tabular}

'have a higher proportion of intra-abdominal fat than women. We were able to examine a few men $(n=16)$ during the course of our study, and they also showed a significant correlation $(\mathrm{p}=<0.05)$ between the ratio of intra-abdominal to subcutaneous fat and the ratio of waist to hip circumference.

Thus the ratio of waist to hip circumference correlates significantly with the amount of intra-abdominal fat and the ratio of intraabdominal to subcutaneous fat but not with the amount of subcutaneous fat. Thus metabolic aberrations may relate more to an excess of intra-abdominal fat than to an excess of centrally placed subcutaneous fat. Although metabolic disturbance may directly cause the preferential accumulation of intra-abdominal fat, an alternative hypothesis is possible-namely, that excess intraabdominal fat leads to the metabolic disturbance. In either case, intra-abdominal fat should be considered harmful.

We thank the radiographers who performed the computed tomography, in particular Mrs J Lawrence, who helped with anthropometry and data collection.

\section{References}

1 Anonymous. The shape of fatness. Lancet 1984;i:889.

2 Vague J. La differenciation sexuelle humaine: ses incidences en pathologie. Paris: Masson, 1953.
3 Kissebah AH, Vydelingum N, Murray R, et al. Relation of body fat distribution to metabolic complications of obesity. I Clin Endocrinol Metab 1982;54:254-60.

4 Kalkhoff RK, Hartz AH, Rupley D, Kissebah AH, Kelber S. Relationship of body fat distribution to blood pressure, carbohydrate tolerance, and plasma lipids in healthy obese women. F Lab Clin Med 1983;102:621-7.

5 Evans DJ, Hoffman RG, Kalkhoff RK, Kissebah AH. Relationship of body fat topography to insulin sensitivity and metabolic profiles in premenopausal women. Metabolism 1984;33:68-75.

6 Krotkiewski M, Bjorntorp P, Siostrom L, Smith U. Impact of obesity on metabolism in men and women. 7 Clin Invest 1983;72:1150-62.

7 Larsson B, Svardsudd K, Welin L, Wilhelmsen L, Björntorp P, Tibblin G. Abdominal adipose tissue distribution, obesity and risk of cardiovascular disease and death: 13 year follow up of participants in the study of men born in 1913. Br Med F 1984;288:1401-4.

8 Lapidus L, Bengtsson C, Larsson B, Pennert K, Rybo E, Sjostrom L. Distribution of adipose tissue and risk of cardiovascular disease and death: a 12 year follow up of participants in the population study of women in Gothenburg, Sweden. Br Med f 1984;289:1257-61.

9 Ashwell $M$. The regulation of the size and nature of energy stores in man. In: Ashwell M, ed Biochemistry of cellular regulation. Vol 2. Clinical and scientific aspects of the regulation of metabolism. Florida: CRC Press, 1980:47-65.

10 Björntorp P. The fat cell: a clinical view. In: Bray G, ed. Recent advances in obesity research. Vol 2. London: Newman, 1978:153-68

11 Borkan GA, Gerzof SG, Robbins AH, Hults DE, Silbert CK, Silbert JE. Assessment of abdomina fat content by computed tomography. Am $\mathcal{F}$ Clin Nutr 1982;36:172-7.

12 Dixon AK. Abdominal fat assessed by computed tomography: sex difference in distribution. $\mathrm{Clin}$ Radiol 1983;34:189-91.

13 Tokunaga K, Matsuzawa Y, Ishakawa K, Tarui S. A novel technique for the determination of body fat by computed tomography. Int $\mathcal{F}$ Obes 1983;7:437-45.

14 Grauer WO, Moss AA, Cann CE, Goldberg HI. Quantification of body fat distribution in the abdomen using computed tomography. Am $\mathcal{f}$ Clin Nutr 1984;39:631-7.

15 Ashwell M, Chinn S, Stalley S, Garrow JS. Female fat distribution-a simple classification based on two circumference measurements. Int $\mathcal{J}$ Obes 1982;6:143-52.

16 Garrow JS. Indices of adiposity. Nutr Abstracts and Reviews 1983;53:697-708.

17 Edwards DAW. Differences in the distinction of subcutaneous fat with sex and maturity. $\mathrm{Clin} \mathrm{Sc}$ 1951;10:305-15.

(Accepted 28 January 1985)

\section{YEARS AGO}

A large part of the mischief set down to pressure, we have always felt convinced, is due to underfeeding; and medical men would, we think, do well to keep public opinion fixed on this subject. In an article calling attention to the demands on the public for the support of special Christmas charities, we are glad to see that the Daily News remarks that, whether free education is within measurable distance, or whether we are not to pay people to teach our neighbours' children, it is certain that the poor little scholars are often very hungry, and very cold, if they be also very learned. It is not difficult to guess what "little forths give in their heads," as one of them says, when they come to school fortified with a humble slice of bread for breakfast, or, perhaps, without even a slice of bread. Dinner may be that of the Barmecide, or little better. Now, what well fed citizen could sit down to hard intellectual exertion at the moment when he has been kept waiting ten minutes without even a glass of sherry and bitters for his evening meal? None of us would like work, none of us but the sailors and soldiers (who are used to it) could do their best in the sad circumstances. (British Medical Fournal 1885;ii:1175.)
Many tons of "butterine," which is a cheap imitation of butter, sent to us chiefly from Holland, are consumed by the poorer inhabitants of the United Kingdom every week. Butterine wants the aroma of true butter, but it is otherwise a close imitation of the original in taste, appearance, and probably also in nutritive value. It is an unobjectionable article of commerce when sold under its proper name, and when wholesome materials only are used in its manufacture. The basis of butterine is the fatty product chemically known as oleo-margarine, and this latter is a clarified oil usually obtained from beef-suet. The fat of a well nourished ox forms about 5 per cent of the entire weight of the animal. This is more than can be used in the ordinary way as food, and much of it has hitherto been converted into tallow-candles. The fat of oxen is now finding a profitable employment as the source of oleomargarine in the manufacture of butterine. In the butterine-factories of Holland, a mixture of oleo-margarine with a small proportion of genuine butter, milk, and vegetable-oil, is well blended by churning; and the product, cooled by ice, coloured, and made into rolls, is the butterine of the shops. (British Medical fournal 1885;i:188.) 